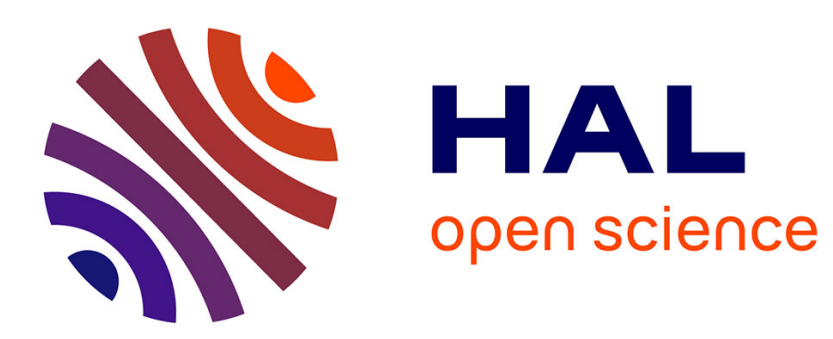

\title{
Three dimensional transport speed of wind-drifted ash plumes using ground-based radar
}

Franck Donnadieu, Sébastien Vallade, Séverine Moune

\section{To cite this version:}

Franck Donnadieu, Sébastien Vallade, Séverine Moune. Three dimensional transport speed of winddrifted ash plumes using ground-based radar. Geophysical Research Letters, 2011, 38, pp.L18310. 10.1029/2011GL049001. hal-00674054

\section{HAL Id: hal-00674054 https://hal.science/hal-00674054}

Submitted on 19 Oct 2021

HAL is a multi-disciplinary open access archive for the deposit and dissemination of scientific research documents, whether they are published or not. The documents may come from teaching and research institutions in France or abroad, or from public or private research centers.
L'archive ouverte pluridisciplinaire HAL, est destinée au dépôt et à la diffusion de documents scientifiques de niveau recherche, publiés ou non, émanant des établissements d'enseignement et de recherche français ou étrangers, des laboratoires publics ou privés.

$$
\text { Copyright }
$$




\title{
Three dimensional transport speed of wind-drifted ash plumes using ground-based radar
}

\author{
Franck Donnadieu, ${ }^{1,2,3}$ Sébastien Valade, ${ }^{1,2,3}$ and Séverine Moune ${ }^{1,2,3}$ \\ Received 21 July 2011; revised 31 August 2011; accepted 31 August 2011; published 27 September 2011.
}

[1] The main utilization of mobile ground-based Doppler radars is to quantify the dynamics of eruptive activity by aiming directly at the emission source. We show that they can also provide information on the initial lateral transport speed of weak ash plumes bent over by crosswind. The method is illustrated by measurements made with a transportable volcano Doppler radar (VOLDORAD) at Arenal volcano, Costa Rica. The near-source displacements of the plume are tracked through echo onsets induced by ash entering successive probed volumes in the radar beam. A constant transport velocity is commonly reached within a few seconds of the initial ash emission, as wind advection and buoyancy take over momentum. The plume azimuth and upraise angles are constrained by comparing the amplitude decrease of the radar echoes as a function of distance from the source with results from a simple geometric plume model. The three dimensional vector of the ash cloud transport speed is then reconstructed with an accuracy of a few percent. This method may have applications for volcano monitoring, for determining pyroclast fluxes, for the modeling of tephra dispersal, and for remote measurements of volcanic gas fluxes. Citation: Donnadieu, F., S. Valade, and S. Moune (2011), Three dimensional transport speed of wind-drifted ash plumes using ground-based radar, Geophys. Res. Lett., 38, L18310, doi:10.1029/2011GL049001.

\section{Introduction}

[2] Volcanic ash clouds, even moderate sized ones, can cause direct hazards to aviation as well as severe economic costs, as recently highlighted by the 2010 Eyjafjöll eruption in Iceland. Subsequent ash fallout may also adversely affect the surrounding population and infrastructures. Tracking of large ash clouds is mainly carried out by means of satellite imagery or by ground-based weather radars. Processed satellite data can be used to obtain maps of the eruptive cloud extension (at intervals of $15 \mathrm{mn}$ to several hours), the mass of $\mathrm{SO}_{2}$, and the concentration and sizes of distal particles. Powerful weather radars, because they operate continuously at a minute-scale acquisition rate, and in all weather, have been used to track the path of large ash clouds [e.g., Harris and Rose, 1983; Rose et al., 1995; Lacasse et al., 2004; Marzano et al., 2011]. Scanned reflectivity maps indicate the height and extension of the plume (within the limit of the radar sensitivity), and mass estimates of distal ash can be derived. However, weather radars can only

\footnotetext{
${ }^{1}$ Clermont Université, Université Blaise Pascal, OPGC, Laboratoire Magmas et Volcans, BP 10448, Clermont-Ferrand, France.

${ }^{2}$ CNRS, UMR 6524, LMV, Clermont-Ferrand, France.

${ }^{3}$ IRD, R 163, LMV, Clermont-Ferrand, France.
}

Copyright 2011 by the American Geophysical Union. 0094-8276/11/2011GL049001 scan large ash plumes within a few hundred kilometers of their fixed location, and often the base of the plume cannot be imaged; thus initial information on the characteristics of the ash plume is generally missing. More recently, dedicated transportable Doppler radars with higher temporal and spatial resolutions have been used with the primary goal of studying eruption dynamics [e.g., Seyfried and Hort, 1999; Dubosclard et al., 2004; Donnadieu et al., 2005]. Since they are set up at a chosen location, these radars can also monitor short-lived weak ash plumes, sound the gas thrust region and provide source eruptive parameters such as initial velocities [Donnadieu et al., 2005] and mass fluxes [Gouhier and Donnadieu, 2008, 2011].

[3] In this paper, we show that they can also provide insights into the dynamics of ash plumes bent-over by crosswinds in the transition region between gas-thrust and lateral spreading, when the beam is wide enough compared to the plume dimensions to capture the bending region. In particular, the 3-D drift speed of ash plumes entrained by wind advection can be retrieved, based on the detection of volcanic ash in beam volumes successively sampled by the radar wave and simple geometric models. The method is illustrated by results obtained from a pulsed Doppler radar on weak ash plumes at Arenal volcano, Costa Rica. Applications for volcano monitoring, estimation of pyroclastic fluxes, remote gas flux measurements, and tephra dispersion models are discussed, along with the limitations of the method.

\section{Data Acquisition}

[4] Data presented in this study have been collected from Arenal volcano, Costa Rica, using VOLDORAD 2, a compact analog of the first ground-based pulsed VOLcano DOppler RADar successfully used at Mount Etna [Dubosclard et al., 2004]. There is very little signal attenuation by hydrometeors at the operating wavelength of $23.5 \mathrm{~cm}$, which enables volcanic particles in the plume to be detected even in overcast weather. Its all-weather operation capacity, along with its variable range of operation $(0.3-11 \mathrm{~km})$, make it an efficient tool both for volcano monitoring and for detailed investigations of ash plume dynamics [Donnadieu et al., 2005]. As released volcanic particles cross the beam aimed at the volcano summit, they backscatter some of the energy transmitted by the radar. Echoes are received back with delay times, which increase from transmission due to the two-way distance run by each wave. Thus the sampled time series corresponds to volumes ("range gates") which are successively probed from further inside the beam (Figure 1).

[5] During the period of February 10-22, 2005, the diurnal explosive activity of Arenal volcano, consisting of discrete, weak ash plumes bent over by a crosswind was recorded. Bad weather often prevented direct observations, but these plumes 

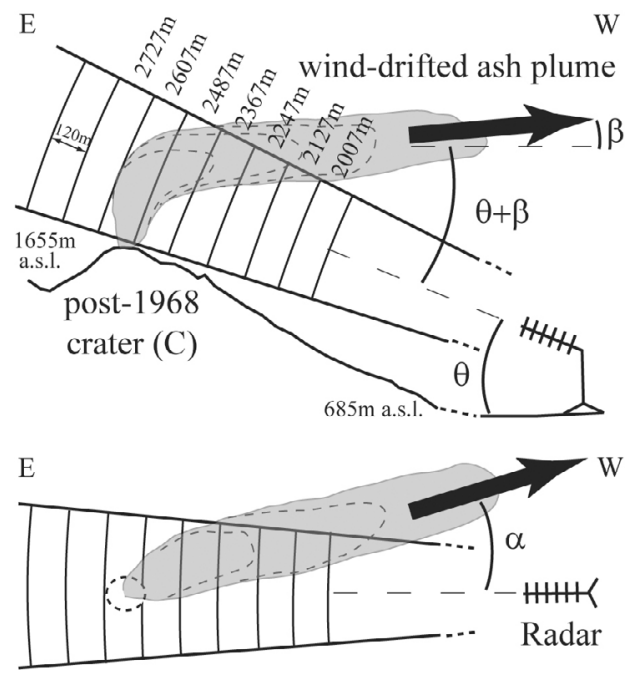

Figure 1. Sketches of the radar sounding at Arenal in (top) section and (bottom) aerial view showing the path of the ash cloud sampled in successive volumes of the radar beam. Whenever the wind direction has a significant along-beam component, the range gates enable the early tracking of the ash cloud displacements through time, providing an estimate of its lateral transport speed. The 3-D transport speed is determined from the plume upraise angle $(\beta)$ and azimuth relative to the radar $(\alpha)$ obtained by best fitting the echo power from 3-D plume geometrical models to data in all range gates. The antenna beam elevation angle $\theta$ is $27^{\circ}$.

commonly reached a few hundred meters in height and were released over a period of seconds to a few tens of seconds. The radar was set up at an elevation of $685 \mathrm{~m}$ a.s.1., $2.6 \mathrm{~km}$ (slant distance) to the west, downwind of and ca. $1000 \mathrm{~m}$ below Arenal's active crater (C). Data were acquired at $\sim 12 \mathrm{~Hz}$ in 11 range gates between 2 and $3 \mathrm{~km}$ from the radar. The resolution was $120 \mathrm{~m}$ along-beam for all range gates, and $410 \mathrm{~m}$ in azimuth and elevation for the $2607 \mathrm{~m}$ range gate where most of the activity was initially recorded. The antenna elevation angle $\left(\theta=27^{\circ}\right)$ enabled the main lobe of the radar beam to hit the top of the cone (Figure 1) and the antenna aperture $\left(9^{\circ}\right)$ was enough to capture the bending of the plume to the WSW due to wind activity. In this way, ash plume displacements could be recorded through up to 7 range gates $(>720 \mathrm{~m})$ before they passed beyond the beam, along with their dynamics right above the emission source.

\section{Methodology}

\subsection{Radar Signals}

[6] Whenever an ash plume forms, volcanic particles cross the antenna beam above the eruptive vent and backscatter some energy to the radar. As the ash plume is pushed by the wind, its front successively enters the sampled volumes downwind and causes power echoes to appear in succession. Meanwhile, the plume body still produces echoes in the previous range gates. Figure $2 \mathrm{a}$ shows typical power echoes from an ash plume at Arenal. Echoes are first recorded in the range gate above the eruptive vent at $2607 \mathrm{~m}$ distance slantwise, and then in 5 more gates down to 2007 $\mathrm{m}$, as the ash plume was bent over by the wind and drifted towards the WSW. Strong ash emissions commonly exhibit a relatively sudden signal onset in the range gate located above the eruptive vent, reaching their maximum amplitude (signal-to-noise ratio up to $10^{3}$ ) in a matter of seconds, and then follow a more gentle decrease over ca. one minute. For this type of event, the ash release may last for several tens of seconds and radial velocities are generally low $(<25 \mathrm{~m} / \mathrm{s})$.

\subsection{Along-Beam Ash Plume Displacements}

[7] An average value of the along-beam speed component of the drifted ash can easily be obtained from the slope of the radial displacements versus the power onset times in the

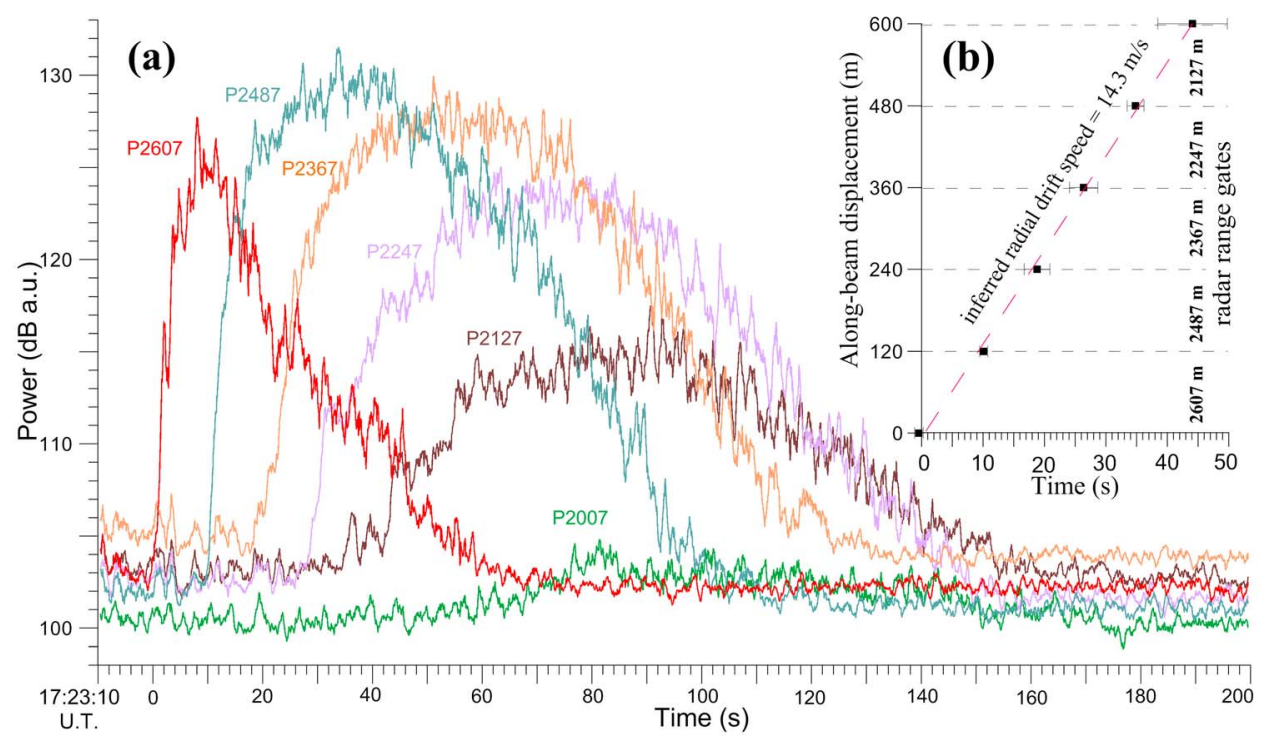

Figure 2. (a) Power amplitude (dB Log scale, arbitrary units) recorded as the wind-advected ash plume crosses 6 successive beam volumes probed by the radar (Arenal, 11/02/2005, 17:23'20 UT). (b) Onset times of ash plume detection in each range gate (120 $\mathrm{m}$ radial resolution). The slope of the linear data fit gives the along-beam component of the ash plume transport speed $\left(14.3 \mathrm{~m} / \mathrm{s}, \mathrm{R}^{2}=0.99\right)$. 


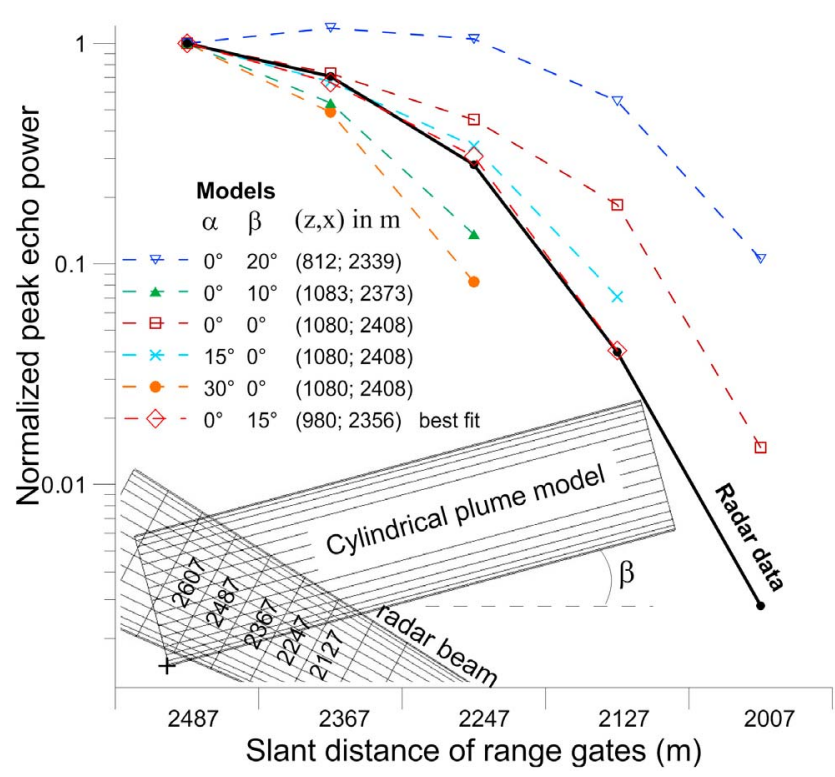

Figure 3. Normalized peak echo power from radar probed volumes crossed by the plume (distance corrected). Black curve is radar data measured on ash plume at Arenal on February 11 2005, at 17:23 UT (Figure 2). Dashed curves are models of cylindrical plume (200 $\mathrm{m}$ in radius) with varied azimuth and upraise angles $(\alpha, \beta)$. A section of the best-fit 3D model is shown as an inset $\left(\alpha=0^{\circ}, \beta=15^{\circ}\right)$. The cylinder base is positioned by coordinates $(x, z)$ relative to the radar.

successive range gates. Ash plume along-beam displacements with time commonly follow a linear trend, indicative of a constant transport velocity $(14.3 \mathrm{~m} / \mathrm{s}$, Figure $2 \mathrm{~b})$. This suggests that buoyancy and wind entrainment take over momentum within a few seconds $(<10 \mathrm{~s})$ of the initial ash release, and is consistent with the low initial radial velocities recorded $(<20 \mathrm{~m} / \mathrm{s})$. The data point from the first range gate $(2607 \mathrm{~m})$ sometimes departs from the overall trend and should not be used in the determination of the drift speed since the plume dynamics and geometry are still controlled by vent location and exit conditions. Slightly concave-upward trends of radial displacements versus time are sometimes observed; they probably reflect an increase in the angle of the plume bending, hence a shorter path through the range gates away from the source, as the wind drag progressively overwhelms the plume buoyancy and residual momentum.

[8] We analysed 8 events with this method and radial components of ash transport speed lie between $6.1 \mathrm{~m} / \mathrm{s}$ and $15.2 \mathrm{~m} / \mathrm{s}$, which is consistent with ordinary wind velocities at the ash cloud altitude ( $2 \mathrm{~km}$ a.s.1.), for which they also provide a lower limit. At this stage, errors on radial speed values (slope of data fit) range from 3 to $10 \%$ as a result of the difficulty in picking onset times when the signal becomes more emerging in the farthest range gates.

\subsection{Transport Speed of 3-D Ash Plume}

[9] The three-dimensional transport speed of the ash cloud $u_{a s h}$ can be inferred from the sounding geometry and plume direction, and from the transit time $\Delta t$ (interval between signal onsets) in the successive range gates:

$$
u_{a s h}=\frac{c \tau}{2 \Delta t} \times \frac{1}{\cos (\theta+\beta) \cos \alpha}
$$

where $c \tau / 2$ is the range gate radial resolution, $\theta$ the beam elevation angle $\left(27^{\circ}\right), \beta$ and $\alpha$ the ash cloud elevation and azimuth angles respectively (Figure 1). The first term in equation (1) represents the radial (along-beam) speed component of the drifted ash determined previously. Below we show how to deduce $\alpha$ and $\beta$ in the second term.

[10] As observed in Figure 2a, radar signals tend to flatten out and decrease in amplitude with distance from the emission source. The relative power backscattered by the volumetric fraction of the ash plume within each range gate can be modeled using simple 3-D geometric shapes to simulate the plume path. By assuming comparable particle concentrations and sizes among the sampled volumes, and compensating for the effect of distance on the radar signal amplitude, the relative variations of the intersection volumes between the beam range gates and the plume are equivalent to relative variations in echo power. Values are thus normalized to the intersection volume of the $2487 \mathrm{~m}$ range gate, having the maximum amplitude (most filled), and compared to the normalized radar power from range gates downwind. Since our objective is to simulate the plume path once it is bent over, the beam filling by the plume in the range gates above the vent and upwind is not considered. Although more sophisticated shapes, for example a reversed funnel progressively bending downwind, could provide better matches for the data in the range gates above the vent, only cylinders are shown because they are quicker to fit and therefore more widely applicable for monitoring purposes. In Figure 3, the normalized power is modeled using a cylindrical plume path for various combinations of $\alpha$ and $\beta$ and cylinder positions above the vent. The diameter of the cylinders $(400 \mathrm{~m})$ was chosen in agreement with common heights observed for ash plumes at Arenal. Since a cylindrical shape does not reproduce plume bending, the modeled plume may exit the beam without intersecting the farthest sampling volumes. Yet, because the plume and beam intersection volumes decrease dramatically downwind with increasing values of $\alpha$ and $\beta$, the plume azimuth and upraise angles can still be well constrained. In the case of Figure 3, both angles amount to $<15^{\circ}$, with a good fit for $\alpha=0^{\circ}$ and $\beta=15^{\circ}$. Using equation (1), the three dimensional vector of the ash plume transport speed $(19.2 \mathrm{~m} / \mathrm{s}$ for the event in Figures 2 and 3) can then be reconstructed from the values of $\alpha$ and $\beta$ with an accuracy of a few percent.

[11] Figure 3 also suggests that the decrease in power amplitude within the first few hundred meters from the vent is dominantly controlled by the progressive exit of drifted ash from the probed volumes, rather than by fallout. This may indicate that, for this type of event, the initial plume emission essentially comprises fine material (ash size) and lacks ballistics.

\section{Potential Applications}

\subsection{Implications for Monitoring and Modeling of Tephra Dispersal}

[12] The early detection and evaluation of the transport direction and speed of an ash plume may improve risk assessment in real-time, particularly for the prediction of areas likely to be affected by ash fallout, and for the early release of alerts. For instance, the along-beam speed component of the drifted ash determined directly from echo onsets, can be used as a minimum transport speed for quickly estimating plume impact times at given locations even without precise knowledge of the plume trajectory parameters. 
[13] Another possible outcome is, importantly, the estimation of the mass flux of tephra and its temporal evolution. Firstly, tephra mass could be derived from radar power time series (as in Figure 2a) by inversion [Gouhier and Donnadieu, 2008]. Then, using the ash plume transit time through the radar beam, the mass curve could be integrated through time to obtain the mass flux evolution. Although this requires assumptions on an average particle size (e.g. from analysis of previous similar events) and unchanged plume bending, the mass flux of tephra is a key parameter needed for plume monitoring and modeling. For long-lasting ash emissions, mass fluxes could be refined repeatedly, possibly within hours, as field observations of particle size distribution are made available.

[14] The quantitative estimates from the radar of the kinetic [Donnadieu et al., 2005; Gouhier and Donnadieu, 2011] and loading parameters [Gouhier and Donnadieu, 2008] could feed volcanic ash transport and dispersion (VATD) models in quasi real-time to help in the assessment of the fallout impact in terms of timing and quantity on nearby areas. Besides, such eruptive parameters, inferred from ground-based Doppler radars measurements near the emission source with high temporal and spatial resolutions, can also complement ash cloud tracking by satellite imagery.

\subsection{Improving Accuracy of Gas Flux Measurements by Remote Spectroscopy}

[15] Uncertainties on the plume velocity constitute the main source of error in volcanic gas flux measurements by miniature UV spectrometers (DOAS, FLYSPEC) or correlation spectrometers (COSPEC) [e.g., Gerlach et al., 1997]. Windbased methods traditionally used to obtain a proxy for the plume transport speed, such as ground-based anemometers, provide poor estimations of the true velocity and introduce large flux errors, potentially exceeding 100\% [McGonigle et al., 2005]. This is because the wind speed at the plume height can differ significantly from that measured on the ground. Moreover, ash cloud transport speeds may differ from the wind velocity at the altitude of the ash cloud, due to the inertia induced by particle loading [e.g., Grafet al., 1999].

[16] When detectable ash is present (cf. Section 5), transportable high-sensitivity radars like VOLDORAD can provide the real plume transport speed in 3-D with greater accuracy. This could help to reduce errors on gas fluxes down to a few percent, especially when an optimum device number or configuration cannot be achieved. In addition, measurements with a single instrument are often made (i) vertically, assuming horizontal plume motion and thus neglecting a possible plume upraise angle $\beta$, and (ii) along existing roads or pathways, not always strictly orthogonal to the plume azimuth $\alpha$. Thus, accuracy can be improved by correcting for the angle components $(\alpha$ and $\beta)$ of the transport speed determined by our method. Moreover, the particle concentration in the radar sampling volumes [Gouhier and Donnadieu, 2008] might also help to quantify errors on gas and aerosols measurements (e.g. $\mathrm{SO}_{2}$ ) due to the ash content increasing UV absorption [e.g. Andres and Schmid, 2001].

\section{Limitations of the Method}

[17] Inaccurate estimates of ash cloud transport speeds will result if the chosen plume geometry strongly diverges from the simple model shape chosen, if plume bending changes with time, or if sedimentation from the ash plume within the first hundred meters has a non-negligible influence on the measured power evolution with distance. The accuracy of $u_{\text {ash }}$ decreases as the ash cloud drift becomes very oblique to the beam because (i) the error propagated from $\alpha$ and $\beta$ increases, (ii) ash is detected in fewer range gates, making data fitting more sensitive to errors on individual data points, and (iii) data are more difficult to match by simple geometric models if only the most bent-over part of the plume trajectory is captured, hence there are less constraints on $\alpha$ and $\beta$. However, an estimate of $\alpha$ can be readily estimated in the field from the approximate wind direction. Transport velocity estimates by this method will be made difficult, or even impossible, in the following cases: (i) side wind is null or blows normal to the beam, (ii) the bending region has a strong upward component or is above the beam (e.g. strong vertical plumes), (iii) degassing involves little or no ash. For instance, $1 \mathrm{~mm}$ ash particles with a concentration inferior to $15 \mathrm{~g} / \mathrm{m}^{3}$ would remain undetected by our radar in this sounding configuration. For dilute plumes, the transport speed retrieval method could be applied even more efficiently using shorter wavelength radars, as these have generally a higher sensitivity to fine ash particles.

\section{Conclusions}

[18] In most cases, a single ground-based radar can ensure the accurate determination of the $3-\mathrm{D}$ vector of the transport speed of wind-drifted ash plumes, using transit times in radar sampling volumes and simple geometrical models. This method may have applications for volcano monitoring, for determining tephra mass fluxes, for the modeling of tephra dispersal and for reducing errors on gas flux measurements. Besides, Doppler radar measurements could also help to constrain the transition from the momentum-controlled ash plume dynamics close to the source to its bending and lateral spreading brought about by wind advection. For this purpose, further modeling on the effects of wind advection on weak plumes, e.g. a continuation of Bonadonna et al. [2005], is also needed.

[19] Acknowledgments. We are indebted to C. Hervier, T. H. Druitt and M. Gouhier for assistance in the field, and to A. Clenet, L. Pouchol and R. Doucelance for help in data processing. Facilities for radar soundings were kindly provided by the Universidad de Costa Rica, ICE and Arenal National Park. Particular thanks are due to M. Mora, G. Alvarado, L.-F. Brenes, F. Arias and C. Ramirez. Funding by the ACI Risques Naturels program of the French CNRS-INSU. We thank Dave Schneider for his review and Ruth Harris for handling the manuscript.

[20] The Editor thanks the anonymous reviewers for their assistance in evaluating this paper.

\section{References}

Andres, R. J., and J. W. Schmid (2001), The effects of volcanic ash on COSPEC measurements, J. Volcanol. Geotherm. Res., 108(1-4), 237-244.

Bonadonna, C., J. C. Phillips, and B. F. Houghton (2005), Modeling tephra sedimentation from a Ruapehu weak plume eruption, J. Geophys. Res. 110, B08209, doi:10.1029/2004JB003515.

Donnadieu, F., G. Dubosclard, R. Cordesses, T. H. Druitt, C. Hervier, J. Kornprobst, J.-F. Lénat, P. Allard, and M. Coltelli (2005), Remotely monitoring volcanic activity with ground-based Doppler radar, Eos Trans. $A G U, 86(21), 201$, doi:10.1029/2005EO210001.

Dubosclard, G., F. Donnadieu, P. Allard, R. Cordesses, C. Hervier, M. Coltelli, E. Privitera, and J. Kornprobst (2004), Doppler radar sounding of volcanic eruption dynamics at Mount Etna, Bull. Volcanol., 66(5), 443-456, doi:10.1007/s00445-003-0324-8. 
Gerlach, T. M., H. Delgado, K. A. McGee, M. P. Doukas, J. J. Venegas, and L. Cárdenas (1997), Application of the LI-COR $\mathrm{CO}_{2}$ analyzer to volcanic plumes: A case study, Volcán Popocatéptl, Mexico, June 7 and 10, 1995, J. Geophys. Res., 102(B4), 8005-8019, doi:10.1029/96JB03887.

Gouhier, M., and F. Donnadieu (2008), Mass estimations of ejecta from Strombolian explosions by inversion of Doppler radar measurements, J. Geophys. Res., 113, B10202, doi:10.1029/2007JB005383.

Gouhier, M., and F. Donnadieu (2011), Systematic retrieval of ejecta velocities and gas fluxes at Etna volcano using L-band Doppler radar, Bull. Volcanol., in press, doi:10.1007/s00445-011-0500-1.

Graf, H.-F., M. Herzog, J. M. Oberhuber, and C. Textor (1999), Effect of environmental conditions on volcanic plume rise, J. Geophys. Res., 104(D20), 24,309-24,320, doi:10.1029/1999JD900498.

Harris, D. M., and W. I. Rose Jr. (1983), Estimating particle sizes, concentrations, and total mass of ash in volcanic clouds using weather radar, J. Geophys. Res., 88(C15), 10,969-10,983, doi:10.1029/JC088iC15p10969.

Lacasse, C., S. Karlsdóttir, G. Larsen, H. Soosalu, W. I. Rose, and G. G. J. Ernst (2004), Weather radar observations of the Hekla 2000 eruption cloud, Iceland, Bull. Volcanol., 66, 457-473, doi:10.1007/s00445-0030329-3.

Marzano, F. S., M. Lamantea, M. Montopoli, S. Di Fabio, and E. Picciotti (2011), The Eyjafjöll explosive volcanic eruption from a microwave weather radar perspective, Atmos. Chem. Phys. Discuss., 11, 12,367-12,409, doi:10.5194/acpd-11-12367-2011.

McGonigle, A. J. S., S. Inguaggiato, A. Aiuppa, A. R. Hayes, and C. Oppenheimer (2005), Accurate measurement of volcanic $\mathrm{SO}_{2}$ flux: Determination of plume transport speed and integrated $\mathrm{SO}_{2}$ concentration with a single device, Geochem. Geophys. Geosyst., 6, Q02003, doi:10.1029/2004GC000845.

Rose, W. I., A. B. Kostinski, and L. Kelley (1995), Real time C band radar observations of 1992 eruption clouds from Crater Peak/Spurr Volcano, Alaska, U.S. Geol. Surv. Bull., 2139, 19-26.

Seyfried, R., and M. Hort (1999), Continuous monitoring of volcanic eruption dynamics: A review of various techniques and new results from a frequency-modulated radar Doppler system, Bull. Volcanol., 60, 627-639, doi:10.1007/s004450050256.

F. Donnadieu, S. Moune, and S. Valade, Laboratoire Magmas et Volcans, Clermont Université, Université Blaise Pascal, OPGC, BP 10448, F-63000 Clermont-Ferrand, France. (f.donnadieu@opgc.univbpclermont.fr) 